\title{
MANAGING LEARNING ENVIRONMENTS IN SCHOOLS
}

\author{
Developing ICT Capable Teachers
}

\author{
Maureen Lambert and Patrick Nolan \\ Massey University, Palmerston North, New Zealand
}

\begin{abstract}
The use of information and communication technology (ICT) in New Zealand educational institutions, as in other countries, has proved to be problematic with outcomes falling far short of expectations. This paper addresses the problem by suggesting a more holistic approach to professional development that takes into account the school-learning environment, including school culture, in an effort to develop educational practitioners as 'all-round' capable ICT-using professionals. To this end, this paper presents and discusses a schematic model of ICT functions and use in school systems, organised hierarchically to accommodate complexity and differentiation between automating and informating functions. The basic argument of the paper is that professional development should be linked directly to the contexts where ICT may be used professionally. Further, development will be optimally effective by identifying and addressing two simultaneous pathways namely, learning and teaching, and administration and management, with emphasis provided during transitions between levels of use. Key aspects of development that support effective ICT use include understanding the multi-functional and multi-tasking nature of the technology, vesting locus of control in users and integrating ICT into everyday professional work. Ongoing research is proposed to further test and demonstrate the efficacy and robustness of the model.
\end{abstract}

Key words: Information and communication technology, professional development, learning environments

The original version of this chapter was revised: The copyright line was incorrect. This has been corrected. The Erratum to this chapter is available at DOI: 10.1007/978-0-387-35689-1_19 


\section{INTRODUCTION}

In an opening address to Parliament in 2002, the New Zealand Prime Minister, Helen Clark, identified information and communication technology (ICT) as one of the three major areas of development for increasing New Zealand economic performance. While all sectors of society, including the economy, will be expected to address the priorities, the response of the education system will be key. In order for the priority to be actualised it will be necessary for education institutions to raise the ICT skills of all learners, from preschool to tertiary, to sustain the demand for life long learning and to meet economic performance objectives. A prerequisite for this to occur will be that teachers themselves become ICT literate and ultimately capable ICTusing educational professionals. Successive New Zealand governments have targeted development in this area as one of the three top development priorities for education (along with literacy and numeracy), with access to ICT tools and professional development a key means to support developments. In reality professional development for ICT use, especially computerised school information systems, has been ad hoc and episodic compared with the other two areas.

\section{PURPOSE}

The purpose of the paper is to present a model for explaining and guiding the professional development of school practitioners as capable and confident ICT-using professionals. The model embodies the findings of research across a range of related areas of use of ICT in education. These include professional development of teachers (McKinnon and Nolan 1989; Education Review Office 2000), the uptake, implementation and use of computerised systems (Nolan, Ayres and McKinnon 1996) and on the role of culture (Stewart 2001). It embodies, equally, contemporary experience of working with New Zealand schools over the past decade that has helped to clarify and make explicit the underlying complexity of the operation of schools, and their various environments and systems that might be better administered and managed with the aid of ICT. The experience, and research (Nolan et al. 2001), highlights specifically the necessity to conceive of professional development in terms of sequences of development as individuals progressively acquire new ICT capabilities and skills necessary to administer and manage a diversity of school functions and activities. In the model, the functions and activities are portrayed as ranging from relatively simple to complex. The ICT systems and tools most appropriate to support them vary similarly in complexity. Thus, professional development 
strategies and approaches are required which can accommodate both, as the individuals who seek and get professional development grow and develop as accomplished ICT-using professionals.

\section{BACKGROUND}

Since formation of the ITEM Working Group 3.7 in 1994, New Zealand research on information technology and educational management has addressed many aspects of this topic. They include virtually all the contents of the Visscher (1996) model of computerised school information systems covering:

- use and levels of use (Nolan 1995; Nolan \& Ayres 1996),

- system development and implementation (Nolan, et al. 1996),

- conceptions of a good school information system (Nolan \& Ayres 1996),

- emerging conceptions of schooling likely to impact on system development and design (Nolan \& Lambert 2001) and

- approaches to professional development for the users and potential users of computerised school information systems (Nolan, Brown and Graves 2001).

Of all the aspects, professional development is the most recurrently problematic and the most important if the potential of contemporary ICT systems and tools is to be fully realised in school education. As discussion below elaborates, currently such realisation is far from happening and the gap between access and use of ICT now available to schools is probably, if anything, wider than a decade ago. The area of teacher ICT literacy continues to be problematic, with technology developments increasingly outstripping the ability of the teaching community to exploit its potential.

\section{ICT PATHWAYS - DIVERGENT EVOLUTION}

Generally speaking, ICT use and conceptions of its use in New Zealand school education over the past twenty to thirty years have been evolving along two separate pathways. This has occurred simultaneously, though somewhat divergently, and in a chaotic not orderly or planned manner. We refer to the pathways here as the learning and teaching (L \& T) and the school administration and management $(A \& M)$ pathways. For the most part, they were laid down for different purposes by teachers and learning theorists on the one hand and school administrators and organisational and systems theorists on the other. Each had seemingly different agendas and 
interests in how and who might best use ICT (or computers in the early days).

The metaphor of the pathway is useful because it suggests a journey that is ongoing with destinations along the way in the form of new developments and ideas about what is possible and what works best, either to promote student learning and development or manage and administer schools better. Recently, two factors that we examine later in the paper, locus of control and accessibility to ICT by an increasingly wider range of users, have influenced the direction of developments and use patterns on both pathways. With learning and teaching, the trend has been towards greater student control of ICT tools for learning and away from teacher control and instructional systems (McKinnon and Nolan 2001). With administration and management, the trend is towards greater participation by teachers supported by computerised information systems, usable in classrooms and across school levels with less emphasis on computer assisted school administration from the school administrative office (Nolan and Lambert 2001). Both trends are occurring in response to new ICT developments. They reflect also a trend toward schools becoming participatory learning communities with a corresponding de-emphasis of the hierarchic organisation aspect of schools. Both trends necessitate not only reconsideration of ways that ICT might be employed for both learning and teaching and school administration and management but also approaches to professional development for teachers and other school personnel in order that they might more readily and effectively access the ICT systems and tools available.

\section{CONVERGENT EVOLUTION}

We believe that such reconsideration is timely because in the last decade or so conversations between users, developers and researchers when the $L \&$ $T$ and $A$ \& $M$ pathways crossed suggest that a convergent evolution is taking place in thinking and developments, replacing the divergent evolution of the past. Two key outcomes have arisen from this. The first is a more holistic conception of how to use ICT in education due to the multi-functionality and connectivity of modern ICT (viz the Internet) which is making ICT much more accessible to and usable by a diversity of users and potential users. The second is individuals (whether teacher, school administrator, student or parent) developing as 'all round' high-level generalist users. In New Zealand schools, school staffs and students alike have access to ICT and Internet connectivity on a par with other countries' school systems. The Government's Information Technology Advisory Group (ITAG 2000) estimates that: 
- Internet access is now available in $96 \%$ of all 2300 New Zealand primary schools and in $99 \%$ of all 340 secondary schools; and that

- In primary schools the computer/student ratio is $1: 13$ and in secondary schools it is 1:7.

While the data on access indicates a seemingly impressive accomplishment in relation to acquisition of ICT across the whole school system, anecdotal evidence suggests that the actual use and levels of ICT use are far less impressive. Researchers and policy makers (ERO 2000) have expressed concern about the disparity between access and use but their concern is no less than that of teachers. A New Zealand survey (Lai, Pratt, \& Trewern 2001) revealed that in the Otago Technology project $86 \%$ of teachers and $88 \%$ of the ICT coordinators identified ICT as the preferred area for professional development.

\section{ICT ACCESS AND USE}

In perhaps the most authoritative international research, Cuban (1999) has shown that teachers vary considerably in the ways they use ICT, from non-users to serious and sophisticated users who utilize of a wide range of applications. Interestingly, he reported that many teachers actively resist even contemplating the use of ICT. In the North American schools of Cuban's research (1999) over 50\% of elementary teachers reported themselves to be ICT non-users. Only 1 in 10 said they were "serious users", e.g., they employed such applications as spreadsheets and databases for the analysis and reporting of student performance and their students routinely carried out multimedia class projects. Also, they typically were the only teachers who used ICT for the management and analysis of school information and to support decision-making and the implementation and review of school policy. In secondary schools, 2 out of 10 teachers were identified as serious users of ICT while $40 \%$ of teachers were reported to be non-users. While no comparable research evidence is available in New Zealand, we would speculate that the situation here mirrors that in North America.

Observers and commentators commonly have explained the disparity between access and use, as being the outcome of teacher resistance. Cuban (1999) argues, however, that such an explanation is not credible. According to Knezeck et al. (2000), resistance is a state of affairs not an explanation of why teachers will or will not use ICT. They propose "will, skill and access" as the three specific conditions necessary to promote teacher uptake and use of ICT with incorporation of it routinely into thinking and practice: 
Will is indicated by positive attitudes toward ICT and the desire to explore its possibilities for particular practical purposes and it can account for up to $40 \%$ of the variance in explaining ICT uptake.

Skill is indicated by level of confidence and competency to perform specific functions within a particular program and likewise it accounts for $40 \%$ of the variance.

Access is indicated by an individual's ability to procure a computer and relevant software for personal use on a regular basis and as needed. This factor accounts for only $10 \%$ of the explanation of uptake but remains important in the sense that without access any progress would be denied.

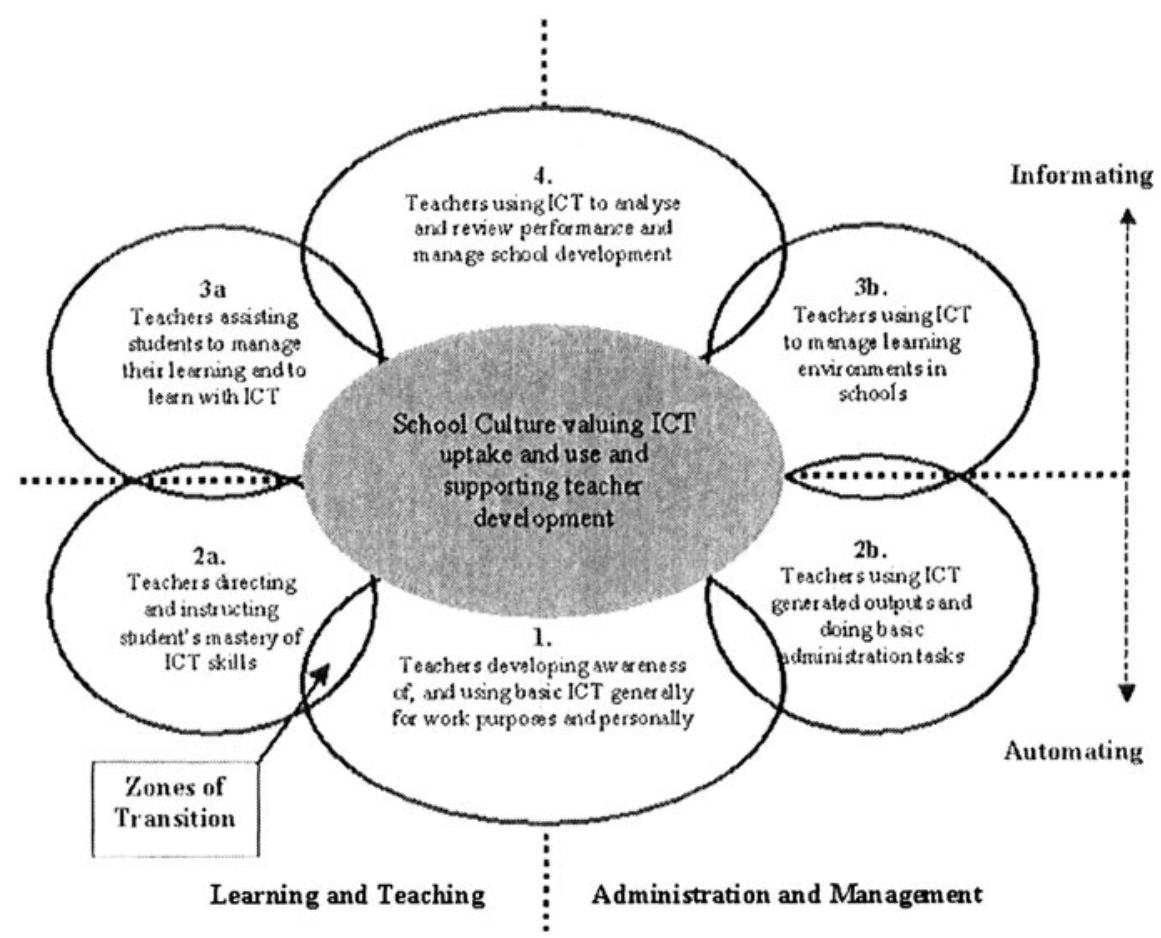

Figure 14-1. A Schematic Model of ICT Functions and Use in School Systems

Professional development in New Zealand has tended to incorporate all three factors but commonly the focus predominantly has been on access at the expense of the development of will and skill. Thus, once the novelty of access has worn off, then in the absence of will and skill the effect of professional development thus conducted tends to wash out in the medium term and ongoing use and development towards more sophisticated use is curtailed. Pockets of professional development around New Zealand that embody the Knezeck et al. (2000) formula have produced more enduring 
outcomes. We suggest here, however, that the potential of the Knezeck et al. research is best likely to be realised when the factors revealed by it are incorporated into a model which encompasses: (i) the full range of types of uses to which ICT can and might increasingly be put; and (ii) the multiplicity and complexity of functions that constitute the essential work of schools. The model presented here for this purpose is outlined in Figure 14-1.

\section{THE ROLE OF SCHOOL CULTURE}

Persistently, experience and research (Nolan et al. 2001; Stewart 2001) show that the presence of a 'school culture which value ICT uptake and use and supports teacher development' to be a condition vital for the ongoing implementation, integration and renewal of ICT use in schools across the two broad L\&T and A \&M domains of ICT use already identified.

In the model, teachers are identified as the key actors in both domains and in each of the six subsets of use and, therefore, they are viewed as the primary recipients of professional development. The term teacher, as used in the model, includes school principals and other school administrators who, by and large, either see themselves as teachers or were teachers at some point. The emphasis on professional development for teachers is consistent with the view that, in the future, the capacity of schools to exploit the real power of ICT in education lies in its widespread uptake and use as distinct from the somewhat privileged access and use of the past in segmented and at times "balkanised" school cultures.

\section{TASK AND PURPOSES}

Our substantive point is this. Even though school administrators may employ various kinds of ICT tools, indeed even a whole computerised school information system, for seemingly school administrative and management tasks, the point and purpose of such use is, or should be twofold:

- Finding ways administratively and managerially to support teachers and students and allowing them access and use of school ICT systems so as to participate in, and contribute to, school administration and management processes as appropriate; and

- Creating and maintaining conditions that improve teaching and facilitate learning. This includes the development of students and teachers as learners, and in so doing permit and encourage wider teacher and student control over, and use of, ICT than in the past. 
The development of schools in the direction of wider ICT access and use will necessitate a shift in mind-set. The shift involves entertaining and embracing alternative and new notions about the nature of schools as organisations and their own capacity to employ ICT in ways that they might not have considered yet. Anecdotal evidence and some case study research (Nolan and Lambert 2001) suggest that the shift is actually happening in specific schools and in educational policy agencies. For instance, the Ministry of Education has developed policies that:

1. encourage routine teacher use of the Internet to access curriculum and teaching resources; and

2. they support the adoption by schools of computerised school information systems usable across internal school levels and by a wide range of school staff.

One way by which the Ministry of Education encourages schools is by requiring that they meet reporting requirements by submitting school information and data electronically and in digital form.

By and large, in New Zealand the developments identified under points (1) and (2) have occurred in isolation. These have been separated by compartmentalised school structures and by different conceptions of how ICT might best be employed, either as learning or as administrative tools and commonly not by the same persons. A curriculum development and research project of the late 1980s and early 1990s (Nolan and McKinnon, 19912000 ) demonstrated how the uses identified in points (1) and (2) could be made interdependent. As students came to use the computer as learning tools, simultaneously the researchers and practitioners in the Project used various programs (e.g., spreadsheet and database programs) to administer the project, plan curriculum programmes, analyse trends in student achievement, and manage project budgets. This diversity of uses in the project was a forerunner to the now emerging contemporary concept of practitioners becoming competent ICT using professionals in a more integrated sense than the specialist ICT user of the past, e.g. the deputy principal managing the school timetable but not using ICT more extensively than this.

\section{LEVELS OF USE}

Individuals who might be classified as 'all-round' competent ICT using professionals would fit within sub-set 4 of the model shown in figure 14.1, capable of employing a full range of ICT tools and processes within and across the L\&T and A\&M domains in any given school. Both ICT tools and processes are further distinguished in the model by the horizontal axis and in 
terms of the automating and informating levels of use identified by Fulmer (1995):

Automating is the routine processing by computer of school data associated with such administrative functions as the entry of student data into teacher maintained records, the processing of school accounts and the compilation of information for external agencies, e.g., the Ministry of Education

Informating is the generation, analysis and integration of information and data by computer to support school management and decision-making at various levels, viz the principal-senior management, departments and classrooms.

According to Fulmer (1995) automating occurs prior to informating processes and automating functions are of a lower order logically, conceptually and technically as indicated in the model by their placement below the horizontal axis line. Informating functions require ICT capabilities that are relatively more powerful and sophisticated even if (and preferably) relatively straightforward and simple to use although greater effort and understanding may be required to master them.

SUBSET 1: Teachers getting orientated to using ICT, developing awareness, gaining mastery of basic program functions and uses and experimenting with simple tasks in either or both the L\&T and A\&M domains, e.g. printing class lists or producing word processed signs for the classroom wall and using the Internet for email.

SUBSETS 2A AND 2B: Teachers having mastered the basic functions of one or more programs and using the programs for specific, probably loosely connected purposes, in a stand-alone fashion. For example in $2 a$, a teacher might be instructing students in the skills of word processing or showing them how to use an instructional program. In $2 b$, the same teacher might complete student reports on screen, fill-in student achievement forms and construct a class timetable.

SUBSETS 3A AND 3B: Teachers confidently and competently use a range of single purpose programs (e.g. a statistical package, CAD program) and integrated suites of programs within and across subject areas. For example in 3a, a teacher might assist students to design and execute an investigation and communicate findings using the following combination of tools, a digital camera, email and facsimile, spreadsheet, database, word processor, multimedia and web pages. In $3 \mathrm{~b}$, the same teacher might be using the same range of tools and purpose designed administrative tools to monitor and assess student achievement, do cohort analyses, and use the results of analyses to plan programmes linked to student achievement levels and interests. 
SUBSET 4: Teachers using a range of ICT (as in $3 a$ and $3 b$ ) as well as accessing and using the computerised school information system (e.g., the Pupil Files data base) to collaboratively examine and reflect upon the implications of achievement across class levels for school performance and improvement, and the formation of school policy, e.g., using the results of ANOVAs on student attendance and achievement in allocating students to classes.

\section{ZONES OF TRANSITION}

In the model, the areas of intersection between circles are called zones of transition. The zones signify movement between levels of use and teacher expressions of interest to learn and do more. The movement and expressions of interest commonly occur when teachers: (i) have, or are developing, an awareness of the potential of the technology to support them to do their work better and more efficiently; and when (ii) they acknowledge the need to develop confidence and competency with a wider range of ICT tools and processes more powerful and versatile than those to which they are accustomed. The latter, in practice, often involves helping teachers make better use of tools they currently use, but which would remain under-utilised otherwise.

Temporally and spatially, zones of transition are places when and where it is timely and strategic to provide professional development and support which addresses three conditions that professional developers must identify and meet in order to achieve meaningful outcomes. They are:

- Accurate diagnosis of readiness and capacity for change in terms of existing ICT knowledge and use patterns and their location within one of the four levels of the model;

- Identification of concerns which may range from orientation to and awareness of ICT capabilities and tools that might next be mastered to worries about refinement of existing skills for implementation and use of systems and tools and the possibility of unintended consequences; and

- Regular and timely challenge, encouragement and support, in context, thereby demonstrating the relevance of the proposed new learning and its potential to produce outcomes of practical and real value.

\section{LEVELS OF USE AND LEVELS OF CONCERN}

Experience of working with beginning ICT users, over many years, suggests that the case for overt, structured and carefully facilitated 
professional development (Nolan et al. 2001), in context, is most important at Level 1 of the model. The key is to first address and resolve the concerns of the persons seeking professional development and/or expected to take up and use a specific ICT tool. To this end, research reported elsewhere (Nolan and McKinnon 1989; Nolan et al. 1996) suggests the efficacy and effectiveness of the Concerns Based Adoption model (CBAM), and its two professional development instruments, Level of Use (LoU) and Levels of Concern (LoC), is most suitable for this purpose. Research using this model has been undertaken in schools, based on its use in development and research projects for implementing computerised school information systems to support school administration and management (see McKinnon and Nolan 1989; and Nolan et al. 1996, 2001 for more detailed explanations).

\section{DISCUSSION}

The refinement proposed here is that if the long-term goal to develop teachers as capable ICT-using professionals is to be realised, then professional development should be encouraged and facilitated on both the L\&T and A\&M pathways simultaneously, and in an integrative fashion. While this integrative aspect is not explicitly articulated and represented in the model of this paper, at this point, the key is likely to lie in the use of common tools and processes (e.g. a word processor and spreadsheet) for dual L\&T and A\&M purposes. In this way, variation of use at introduction is likely to consolidate skill acquisition and understanding of use and by reinforcing in the minds of users the multifunctional nature of the technology and the multiple tasks that it can usefully serve under their control.

With professional development viewed this way, teachers are more likely to shift the locus of control over the technology to themselves and become inured to using it routinely and to integrating it more effectively into their professional work and into the learning and teaching environments in which they work daily.

Beyond Level 1, the processes of CBAM remain useful; indeed, they provide essential tools for identifying professional development needs and for the structuring of ongoing professional development at higher levels of use. In so far as teachers have internalised locus of control at Level 1, then it is expected that they will take responsibility increasingly for initiating and conducting their own professional development through subsequent stages. Perhaps they will work collaboratively with peers and thereby promote and develop environments conducive to ongoing professional development and learning, thus promoting the growth of a school culture of the kind described 
at the outset that values both ICT and its use by competent ICT using professionals.

Importantly, while the locus of control over use of the professional development instruments of CBAM may shift, say, from external consultants to the teachers themselves, in order to continue being effectively used, the internal structure of the Levels of Use and Levels of Concern instruments should not be altered, at least not without good grounds for doing so based in experience. This is because empirical evidence of using them in many different professional development contexts has demonstrated the efficacy of the levels structure within each instrument. For example, with the Levels of Use instrument, mechanical use precedes routine use almost universally across different professional development contexts and integration, refinement and renewal follow in sequence, although the period for each may vary as a function of users' knowledge of, and competency in using, a particular ICT tool or system. For instance, a teacher already well versed in multimedia for both L\&T and A\&M purposes might move more quickly to working in a web-site development environment than a teacher wanting to do so but from only Level 1 or 2 competency with word processing. In this case, it may be necessary to acquire prerequisite knowledge and skills at an intermediate level and the Levels of Use and Levels of Concern instruments once operationalised for use at these levels would provide the specific professional development tools required.

Work done to date in this direction suggests the potential fruitfulness of using the CBAM instruments in this way, although ongoing research and development of a practical nature is required to specify the particular content of the Levels of Use and Levels of Concern instruments within each use level of the ICT Schematic Model of this paper.

\section{CONCLUSION}

The model and associated ideas presented here are but another step on the pathway towards a developed, fully ramified and empirically validated explanation of the role and structure of professional development to foster teachers' mastery and use of ICT systems and tools for multiple purposes in education and assist them to more fully exploit the power of modern ICT for education. In New Zealand, a program of professional development work arising from the ideas that lead to this paper is soon to commence and it will consolidate and build upon the work done to date. It is our hope that others may see value in the model and the ideas of the paper and in due course report the outcomes of ongoing work at subsequent WG 3.7 ITEM Conferences. 


\section{REFERENCES}

Cuban, L. (1999). Why are most teachers infrequent and restrained users of computers? Report from the Fifth Annual Public Education Conference, Vancouver. Available at: <http://www.bctf.bc.ca/parents/PublicEdConf/report99/appendix1.html>

Education Review Office. (2000). In-Service training for teachers in New Zealand schools. No.1. Wellington.

Fulmer, C.L. (1995). Maximising the Potential of Information Technology for Management Strategies for Interfacing the Technical Core of Education. In Information Technology in Educational Management, Barta, B-Z., Telem, M. and Gev, Y. (eds.). Chapman Hall, London

ITAG (2000, March). ICT in Schools 1999. Available at: <http://www.med.govt.nz/pbt/infotech/ictschools1999/index.html>

Lai, K.W., Pratt, K., \& Trewern, A. (2001). Learning with Technology: Evaluation of the Otago Technology Project. Dunedin: The Community of Otago Trust.

Knezeck, G., Christensen, R., Hancock, R., \& Shoho, A. (2000). Toward a Structural Model of Technology Integration. Proceedings of the Annual Hawaii Educational Research Association.

Ministry of Education (1999). Interactive strategies for schools. Ministry of Education, Wellington.

McKinnon, D.H. and Nolan, C.J.P. (2000) A longitudinal Study of Students' Attitudes towards Computers: Resolving an Attitude Decay Paradox. Journal of Research on Computing in Education 32(3), 325-335.

McKinnon, D.H. \& Nolan, C.J.P. (1989). Using Computers in Education: A Concerns-based Approach to Professional Development for Teachers. The Australian Journal of Educational Technology, 5(2) 113-131.

Nolan, C.J.P., Brown, M.A. \& Graves, B. (2001). MUSAC in New Zealand: From Grass Roots to System-wide in a Decade. In. Information Technology in Educational Management: Synthesis of experience, research and future perspectives on computerassisted school information systems Visscher. A.J., Wild P. and Fung, A.C.W (eds). Kluwer, Holland.

Nolan, C.J.P. and Lambert, M. (2001). Information Systems for Leading and Managing Schools: Changing the Paradigm. In Pathways to Institutional Improvement: Information Technology in Educational Management, Nolan, C.J.P., Fung, A.C.W and Brown, M.A. (Eds.). Kluwer, Holland.

Nolan, C.J.P. and McKinnon, D.H. (2000) Integrative Secondary School Education and IT Augmented Learning. 7th SEAMEO INNOTECH International Conference: Knowledge Networking in the World of Learning. Manila: Philippines.

Nolan, C.J.P., \& Ayres, D.A. (1996). Developing a Good Information System for Schools: The New Zealand Experience. International Journal of Educational Research, 25(4), 307321.

Nolan, C.J.P., Ayres, D.A. Dunn, S. and McKinnon, D.H. (1996) Implementing Computerised School Information Systems: Case Studies from New Zealand. International Journal of Educational Research, 25(5), 335-349.

Nolan, C.J.P. (1995) The Development of Computer-assisted School Administration in New Zealand. In Information Technology and Educational Management, Barta, B.Z., Telem, M. and Gev. Y. (eds.). Chapman and Hall, London. 
Nolan, C.J. P., McKinnon, D.H. and Soler, J. (1992) Computers in Education: Achieving equitable Access and Use, Journal of Research on Computing in Education, 24(3), 299314.

Nolan, C.J.P. and McKinnon, D.H. (1991) A Case Study of Curriculum Innovation in New Zealand: The Freyberg Integrated Studies Project, Curriculum Perspectives, 11: 4, 1-10. Stewart, D. J., 2000. Tomorrow's Principal Today. Kanuka Grove Press, Palmerston North New Zealand.

Visscher, A.J. (1996). Information Technology in Educational Management as an Emerging Discipline. International Journal of Educational Research, 25(4), 291-296. 
SECTION 5

REPORTS FROM DISCUSSION GROUPS 